\title{
Metaphors of Faith and Routine Resistance: First Tier Managers in Further Education
}

\author{
Damien Page \\ University of Greenwich, UK
}

\begin{abstract}
Drawing on a study of First Tier Managers (FTMs) in further education colleges, this paper presents a typology of the role based upon metaphors of faith. The study found that faith in their work and in the transformational potential of education was an essential element of FTMS' motivation, hardiness and coping strategies and positioned each manager as fundamentalist, priest, convert or martyr. The paper argues that faith is also an important antecedent of organisational resistance and that the types of workplace resistance enacted are determined by the metaphorical faith positioning of each manager. It concludes that, while faith is an essential part of employee motivation, it also fuels the likelihood of resistance when that faith is challenged.
\end{abstract}

\section{Introduction}

In the post-bureaucratic workplace, Tayloristic principles of organisation have, it is argued, largely given way to management's enaction of strategies to gain the commitment of employees [1]. Whether through teamwork, performance management, participative management, collegiality or discursive enculturation, the concern of senior managers is to cultivate employees that share the vision, values and objectives of the organisation. However, the success of gaining the commitment of workers often rests on notions of faith, especially in education which has, according to Jauhianunen and Alho-Malmelin, "taken over the role and functions of the church as the producer of morals that create social cohesion ${ }^{\text {ee }}$ [2]. As such, to ,add analytical depth and richness ${ }^{\text {ee }}$ [3], religion may function as a metaphor in the analysis of educational organisations. We may think of the vocation of teaching, its ethical framework, its moral and social purpose and its conferment of symbolic „productse such as degrees and titles. However, Jauhianunen and Alho-Malmelin [2] only present this religious metaphor from the position of the learner, the seeker or non-seeker of educational salvation or damnation; they do not consider those within the holy order, those who participate in the institutions of faith/education. From this alternative position, this paper draws upon a study of First Tier Managers (FTMs) in further education colleges and discusses a four part typology of FTMs based on four metaphorical faith positions: fundamentalist, priest, convert and martyr. It then argues that the faith positioning of FTMs directly influences the way they resisted senior managers within their colleges and the types of resistance that were enacted.

\section{The study}

This research was conducted in four general further education colleges called here Woodside, Parklands, Eastshire and Blackton. The purposive sampling consisted of 27 first tier managers (FTMs), often called Curriculum Leaders or Programme Managers, from a wide range of cognate subject areas including construction, health and social care and A levels. Beginning with the use of the critical incident technique [4] to establish the major areas of focus, each FTM was interviewed three times over the course of an academic year and the interviews were transcribed in full before being analysed according to grounded theory principles, incorporating axial coding. In addition, supplementary methods were used to triangulate the data including a survey of principals, focus groups of lecturers and documentary analysis of job descriptions and person specifications.

\section{Management faith: the case of first tier managers}

First tier management was found to be a difficult role and the difficulties began at appointment moving from being a member of a team to managing former peers was often a tricky transition to manage:

Linda: It was more difficult because I've come from being one of their colleagues and then suddenly I'm in the position where I'm observing them and I don't know how they feel about that... I think coming from being alongside them to suddenly having to - not being above them but having to do things where I suppose you are in a way, you are managing them so it is, yeah, that"s probably a hard thing.

Working in a performative environment, FTMs were engaged in satisfying a trialectic of students, their team and the organisation, each exerting their differentiated influence and demands on the time and energies of the FTM. As such, the role was found to be elastic, stretched in different directions, striving to 
meet the immediate gratification needs of the FE system where every new request is the most important and has to be met immediately. As a result, stress was a regular feature in the lives of FTMs. Yet they were hardy individuals: they came to work each day, they ploughed through their never ending to-do lists, they struggled with the intensive emotional labour of their work. For some, perhaps, such persistence was the result of the fundamental need for income and the comparative bleakness of the contemporary FE job market. For the majority, however, the reason they came to work each day, the reason why they endured the difficulties of the role, was due to belief - they believed in education, in FE in particular, and they believed that what they did made a real difference in the lives of their learners.

Jim: it's a belief in what you're doing and doing what you're doing for the right reasons. If you're in teaching for the pension, you're not in for the right reasons. If you're here because you really believe in young people and you really believe you can provide skills and give them a chance, an opportunity, then that should come across in the attitude, in the way you behave, the way you act, the way you do your job.

Their belief motivated them and drove them to maximise student success, whether it was defined in terms of qualification achievement or behavioural modification, whether preparing them for university or the workplace. It was belief that pushed them through the "fire-fighting ${ }^{\text {ee; }}$ it was belief that helped to ameliorate the continual changes within their colleges; it was belief that drove them to jeopardise their wellbeing in meeting the demands of their role. Yet their faith in their work was not homogenous and was mediated by their perception of their role, its purpose and, most importantly, which element of the trialectic of student-team-organisation that they prioritised. Drawing on metaphors of faith, a four part typology of FTMs was devised that positioned role incumbents as fundamentalists, priests, converts and martyrs [5].

A justification of the choice of titles for each of the types should, however, be made. The terms especially „fundamentaliste and "martyr" - are clearly emotive and connotatively loaded, yet this was a deliberate attempt to highlight the strength of feeling among the participants about their role and their understanding of the organisational context that arose from the data. Fundamentalists saw themselves precisely in those terms and saw the increasing financial imperatives of their college as profane and heretical. Their fundamentalism was a deliberate oppositional positioning as an attempt to reappropriate the educational terrain from senior managers. Similarly the accounts from martyrs foregrounded the deleterious effects of the role upon their health. With this in mind, the titles were deliberately chosen as those which were most representative of the depth of feeling that FTMs exhibited.

\subsection{Fundamentalists}

Fundamentalists were those FTMs who foregrounded the student experience and believed most fervently in the purpose and principles of further education. Almond et al. [6] define fundamentalism as

a discernible pattern of religious militancy by which self-styled, true believers ${ }^{\text {ee }}$ attempt to arrest the erosion of religious identity, fortify the borders of the religious community, and create viable alternatives to secular institutions and behaviors.

For fundamentalist FTMs, the militancy is educationally-driven and a reaction against the financial imperatives that increasingly define their work; the identity being eroded is that of an autonomous, professional lecturer; fortified are the borders around the educational community, inclusive of students and teachers but repelling senior managers. Fundamentalist FTMs are the most devout adherents to the doctrine of student welfare and the „educational salvation ${ }^{\text {ee }}$ (to use Jauhiainen and AlhoMalmelin "s term [2]), offered by FE as the ,secondchance sectore and perceive themselves to be teachers before all else - „manager ${ }^{\text {ee }}$ is a title, not an obligation and students were prioritised:

In the data from fundamentalist FTMs, accountability was evident, but it was not the variety of accountability ensconced with the performativity mechanisms of Ofsted, benchmarking and league tables. Accountability for fundamentalists was moral and social and measured in terms of student welfare and success. However, even ,success ${ }^{\text {ee }}$ tended to be accounted for in different terms and embraced behavioural transformation and skills-acquisition before pass rates and retention percentages. As such, fundamentalist FTMs were those who positioned themselves against senior managers and service departments in the most oppositional terms; as a result, tasks that were perceived to be managerial or administrative were attended to only after the completion of pedagogical and pastoral duties.

Elaine: To me, teaching comes first and if $I^{\text {ee }} v e$ got to teach then I can ${ }^{e e} \mathrm{t}$ do whatever report they want. If $\mathrm{I}^{\mathrm{ee}} \mathrm{m}$ teaching for five hours in that day then that ${ }^{\text {ee }}$ got to wait until teaching ${ }^{\text {ee }}$ s finished and I can't do that unless they"re [senior managers] going to give me the time. 
Amanda: The way I view my job is that first and foremost I am here to provide for the students... theyere my number one priority and then thereafter the teaching staff would be number two and my line manager would unfortunately only get to be number three [laughs] on my list on a good day.

That is not to say that teaching was a priority in isolation. Fundamentalists tended to prioritise the whole student experience rather than just their personal classroom activities. Here then, although „managere was an often disavowed term, fundamentalists had embraced their enhanced role to some extent, explicating their area of responsibility in terms of students"e entire wellbeing while at the college. Seen objectively, they were fulfilling the managerial role even while distancing themselves from the organisational understanding of „managerial ${ }^{\text {ee }}$. For fundamentalists, being managerial was equated with compromising the prioritization of students:

Grace: I never want to be a tutor where $I^{\text {ee }} \mathrm{m}$ going along the corridor and a student comes up to me clearly needing some help or advice [and] say "I"m sorry I haven"et got time". I never want to be that way because the students, to be honest with you, their welfare, how they feel, their experience with us is a hundred times more important than any amount, any document $\mathrm{I}^{\mathrm{ee}} \mathrm{m}$ really going to write.

\subsection{Priests}

Team-focused FTMs are priests, ,representative of a society"s deity" whose duty is to ,ease the supernatural relationship between human and god ${ }^{\text {ee }}$ [7]. But, in addition, priests are also representatives of the church and its structures. In the FTM context, priests are the advocates for their teams, interceding between the often mysterious and unknowable ways of senior management and the congregation of the devout (lecturers) and focusing on the administration of the rites of HRM. While priests are equally supportive of the salvation-potential of FE, salvation here was to be attained by the skilful and moral management, support and motivation of their teams (or acolytes) rather than prioritising their own relationship with learners:

Pat: I'd like to think initially it was support. I always thought it was support when I came into it. I just wanted to make sure that if there were problems that I would be seen to be there to help in whatever way I could... my personal opinion is it's [the role] there to support. And of course if you're there to help and you get the support, the other things fall into place, I've found.
In addition, while performance management rites such as internal observations often adopted a selfflagellant aspect in colleges, for priests the observation of their team was an opportunity to facilitate development for the good of the learners. Similarly, the rite of appraisal with its shades of the confessional [8] [9] was transmogrified from its performance management origin to a means of identifying professional development and recognising achievements:

Jan: Personally I find that side of it the most rewarding where you"re working with somebody - particularly if they"re new to teaching - and you can give them some time and a sounding board and point them in the direction of things and see if they respond well, appreciatively. I find that really rewarding.

Where fundamentalists positioned themselves (even if only cognitively) within the teaching team, priests recognised their separation and foregrounded the discourse of cooperation between themselves and the lecturers they managed. Their hierarchical rise was discussed in terms of emergence - they all described how they had been fulfilling many of the FTM duties before taking on the role officially; promotion (ordination) was merely a conferment of title upon the leadership practices they performed on a daily basis. They generally accepted the title and obligations of a managerial position but saw their role as a means of facilitation - their raison d'être was to make the professional lives of their team easier, thus providing increased quality of teaching and learning.

\subsection{Converts}

Organisation-focused FTMs are converts. Conversion here is a matter of ,institutional transition $^{\text {e }}$ [10], the movement from one sub-group to another in a larger religious tradition. Convert FTMs are those who most self-identify as managers rather than teachers, accepting and promulgating the discourse of the almighty, a zeal for the financial imperatives of the contemporary college where students are customers and pass rates are equated with organisational survival. Here, administrative, reporting and managerial tasks are prioritised above learning and teaching concerns.

Abbie (Parklands): I like the job - managing - I like it a lot. I feel I'm using my skills much more... I think the teaching I do is fine, it "s good to keep in touch with the students, it "s good to keep in touch with that and not lose it completely but I think the interest for me is more in management and the bigger picture I suppose, what we ee re going to do with the department. 
While the adoption of business practice within colleges was considered profane or heretical by fundamentalists, converts were acutely aware of the pressures of governmental policy levers that forced colleges to focus keenly on financial matters. It is also significant that the majority of FTM converts in this sample had come from the private sector „tradition transition"e in Rambo"s terms [10] - and brought the discourse of commercial survival. However, transitioning from the private sector to the public sector often brought frustration for converts who were used to business practices that emphasised speed and efficiency of decision making.

Converts were also highly aware of college strategy and how it related to their particular context. More than any other type of FTM they attended senior management open-invitation meetings and shaped the management of their teams according to a strategic plan. In addition (and it was likely connected) converts were the most likely to speak explicitly about their desire to be promoted.

Jim: It's great getting that student interaction and things, but to progress and move on you need to get away from that, so, as a personal development thing, I obviously want to go up to a more senior position, so, you know, you've got to get away from the teaching, but it does take you a little bit away from what's going on down there on the shop floor so to speak.

While they did not necessarily relish the extensive data collection and reporting tasks required of them, they understood the importance of these processes to institutional survival and also understood that speed and skill in these matters were highly valued in the contemporary FE sector and were likely to expedite promotion.

\subsection{Martyrs}

Finally, there are the omni-focused FTMs, martyrs, those who ,should choose to be forgotten, mocked or exploited but never understoode [11]. Martyr FTMs are those who bear the demands of the trialectic most keenly, sacrificing health and wellbeing - a signature of martyrs according to Cook [12] - for the good of others and the sanctity of their beliefs in the transformative potential of education. While fundamentalist, priest and convert FTMs all exercise significant agency in their alignments, martyrs attempt to satisfy each constituent element of the trialectic and are dragged between foci depending on the current imperative. As such, martyrs are the type most subject to home invasion.

Sue: You feel a bit like a carthorse or a mule [laughs] - everybody kind of thinks that they can just keep beating you til one day you roll over with all your legs in the air and [they] think "oh hang on, maybe she wasn't coping that well”.

Yet despite the impact of the role upon wellbeing and health, martyrs often adopted a belligerent defiance in their accounts - they were determined to meet the needs of all elements of the trialectic:

Vicky: We are quite a belligerent bunch because we have to be to survive because if I did everything I was asked to do I would be a nervous wreck, I'd be in hospital by now because it's just not possible

In this we see the determination to make a ,prosocial difference ${ }^{e e}$ in Grant ${ }^{e c}$ s terms [13]: they are „employees who see their work as a calling [and] want their efforts to make the world a better place ${ }^{\text {ee }}$ (p393). Yet this altruism was accompanied by a resignation that, despite their best efforts, they were unable to devote enough attention to learners which created significant levels of guilt, a form of cognitive mortification to extend the religious metaphor. There was also the sense in their accounts that they never did enough, no matter how many hours they worked and how much effort they put in as the ,relational architecturee $^{\text {ee }}$ [13, p395] emphasis on management and administrative tasks reduced the motivation they enjoyed from student contact. For martyr-FTMs, the role was sisyphean.

\section{Management faith and resistance}

The faith positioning of FTMs did not just affect how they operated and how they managed - it also affected how they resisted. The resistance of managers is a neglected area of research that perhaps arises from the binary opposition of „management ${ }^{\text {ee }}$ and ,resistance ${ }^{e e}$. In the dichotomous view, power is often reified with research focusing on the indomitable mechanisms of control that subsume and ultimately extinguish resistance. Alternatively, resistance is sometimes reified and romanticised to such an extent that resistance is found in almost every action. Such a binary approach frames employees as managers or workers, appropriators or re-appropriators, colonists or space-seekers, controllers or resisters. From this perspective, managers are conceptually precluded from resistance. But management is not homogenous and hierarchical position is no measure of acts of subordination. As this research makes clear, managers are just as likely to resist as other workers as they ,share in the subjugation and oppression that characterizes the lives of production workers ${ }^{\text {ee }}$ [14]. Instead of adopting a dichotomous approach, managerial resistance should be positioned within the dialectic of power and resistance which allows us to focus on the ,interpretive struggles among 
discourses and practices ${ }^{\text {ee }}$ [15] and engenders a consideration of control and resistance wherever it is locally and socially produced [16]. Adopting this perspective allows us to view FTMs both as managers and managed.

The issues of simultaneously managing and being managed were highlighted throughout this research right from the very first round of fieldwork, FTMs were found to be resisting [17]. The sheer range of resistant strategies employed by the FTMs must be seen on a continuum and can be framed by the faith typology discussed in the previous section. At one end are the overt forms of resistance: principled dissent, direct confrontations and refusal were all reported as means of responding to senior managers who were generally reviled by the participants in the study. Yet overt resistance was not adopted equally by the four types of FTMs: martyrs were the type most likely to openly - and sometimes publicly signal dissent directly to senior managers. By reference to their position within the trialectic, we may find an explanation for the propensity of martyrs to resist overtly: martyrs are those FTMs most subject to the combined forces of students, team and organisation and, as the data suggest, the result is a high level of stress and a concomitant detriment to health. It is likely that, in trying to meet the needs of the three elements, overt resistance is the final recourse once personal coping strategies have been exhausted as can be seen in Vicky's case:

Vicky: At the end of April I just went into one of the director's offices and said "right, this is my staff request and they've been with you for weeks and either you approve them and let me recruit" I said "or you find someone to replace me". The next day the vice principal said "I've approved your staff request".

In addition, few martyrs wished to proceed further up the management hierarchy and it is likely that this contentment with their current tier meant that they felt less constrained by careerism and therefore more able to resist. However, while perfectly willing to engage in overt resistance behaviours, martyrs were found to be less likely to pursue covert forms; here, then, appeared to be the terrain of the fundamentalist, priest and convert. However, again we find that different types of FTM were more predisposed to certain types of resistance.

Converts, with an inclination to climb the management hierarchy, avoided overt forms of resistance, presumably for fear of damaging their promotion prospects. However, converts were found to be the group most likely to engage in resistance by distance [18] - they were the only group that routinely reported the ability to ,switch offece
Carol: I switch off at the weekends I make myself yeah. I ${ }^{\text {ee }}$ ve got a lot of other things in my life. $I^{\text {ee }}$ ve got a family that has to be looked after so yes, I just make myself, make myself.

Despite identifying with their colleges, work was strictly compartmentalised from their private lives. With the organisation prioritised in this metaphorical faith position, those elements of the trialectic that demanded the most intense emotional labour - teams and students - were distanced which perhaps engendered the ability to separate the self from work. This distance was only enacted away from the workplace, never within, which meant that the observable daily behaviours were still those of the convert and, from an external perspective, nonresistant. This ability to distance the self from work may also be connected to the background of the converts, almost all of whom had come to teaching as a second career, mostly from industries that lacked the intensity of emotional labour demanded by careers within the education sector [19]; as such, they may have arrived in FE with a heightened ability to see work as work rather than as a vocation.

Interviewer: How easy do you find it to switch off at the end of the day?

Jim: Very easy I think. I've just got that ability; I can just walk out of here and leave it...When I'm here, I'm working and I'm committed to it. When I'm at home, I'm at home.

The final two types of FTMs - priests and fundamentalists - were those categories that employed the widest range of covert resistant behaviours but there were also differences. As the self-appointed intercessors between their teams and more senior managers, priests were the FTM type that most regularly engaged in granting favours to members of their teams. While they lacked the formal power to offer tangible (and official) rewards, priests would regularly allow members of their team to arrive late or leave early to make up for overtime or if a private matter necessitated absence. Having fully adopted the devolved HRM role, priests were acutely aware of the bureaucracy and ,needless complexity ${ }^{\text {ee }}[20]$ of formally requesting flexibility in their team"es timetables; as a result, priests would keep such favours quiet - the transactions were between them and the individual member of their team.

However, it was fundamentalists who engaged in the widest range of covert routine resistance and most common were various forms of ,making out ${ }^{\text {ee }}$, [21] [22] those behaviours that ,work the system, subvert or manipulate the official practices of the workplace $^{\text {ee }}$ [23]. Fundamentalists regularly cut corners on managerial and administrative tasks, estimating statistics rather than devoting time to data 
retrieval and precise calculations. In addition they would employ ignoring as a routine response to requests, especially when those requests came from service departments such as MIS or Human Resources, those departments that lacked direct control and formal power over FTMs. John, for example, had been asked to conduct a returning to work questionnaire with a lecturer who had been off sick:

John: I've now got to interview him about [his illness] but I just don't really think that ${ }^{\text {ee }}$ s my job you know, it's either personnel or the [middle] manager's job, you know. It's still sitting on my desk at the moment... so I might just ignore it and it probably will go away.

Yet their primary method of resistance was discursive: the very fact that they adopted a fundamentalist perspective and discourse placed them in direct opposition to the senior managers who they considered value-less and impelled only by financial imperatives.

The discussion here focuses only on the primary methods of resistance of each of the four faith positions and is not meant to be exclusive: converts also sometimes ignored requests; martyrs also occasionally distanced themselves; priests and fundamentalists also performed acts of principled dissent. The aim here is to highlight how the positioning of FTMs - whether agentively or by means of top-down job design - may invite a proclivity to adopt specific forms of resistance. But while the overt-covert continuum is one means of classifying acts of resistance, there is another, one that focuses on the potential impact of resistance. While for writers such as Contu [24] and Young [25] organisational resistance is often , ,decaf ${ }^{\text {re }}$ and lacking impact, this research highlights those forms of managerial resistance that are likely to be impactful, the ,espresso resistance ef of managers (to continue the coffee metaphor): short, strong actions such as principled dissent, ignoring and refusal that are oppositional and do not merely activate a ,specious sense of freedom ${ }^{\text {ee }}$ [26] but temporarily disrupt and suspend the mechanisms of control that operate within colleges.

\section{Resistance by Collusion?}

The faith positioning of FTMs did not just influence the types of resistance they enacted themselves, it also affected their proclivity to challenge or collude with the resistance of their teams. Fundamentalists and priests were more likely to turn a blind eye to resistance performed by their teams, but for different reasons. Ignoring or colluding with resistance for fundamentalists appeared an attempt to avoid being identified with
„Management" ${ }^{\text {"e }}$ For some, this dis-identification was ideological, a reaction to the value-less and financially-driven leadership of their college; for others, dis-identification was pragmatic and a means to prevent a loss of cooperation from fellow teachers. Priests were equally likely to turn a blind eye but here the concern was with not damaging their relationships - both personal and professional - with the members of their team, not necessarily for the risk of withdrawal of cooperation but because these relationships were valued so greatly, the quality of the leader-member exchange [27] being a crucial part of the priest identity.

In stark contrast were converts and martyrs who were the types most likely to confront and challenge even routine forms of resistance but, again, the reasons differed. For converts, resistance was a challenge to their authority. Even if it wasn ${ }^{\text {eet }}$ aimed at them, their identification with the organisation meant that resistance to senior managers was resistance to them as well. Furthermore, failing to challenge resistance could also be seen as detrimental to the career advancement of converts progression to more senior positions was unlikely if resistance at team level went unchallenged. Here then, within the act of challenging, was an admission of complicity in the acts of subjugation that occurred within the colleges. However, we must remember that converts were found to be the FTM-type least likely to resist within the working day - resistance for converts was an act of distancing the self from the college after hours. As such, it appeared that they expected the same from their teams - resistance should be in their own time.

While martyrs were also likely to challenge resistance, the reasons were different. Resistance for martyrs was seen as potentially damaging to every element of the trialectic and, as martyrs were already struggling to meet all needs, resistance held the potential to topple the balance and undermine everything they were trying to accomplish. Most martyrs were also those who held the widest span of control in their top-down job design, managing the largest teams. While we may suspect that managing the largest teams would lead such FTMs to adopt a position of priest and a prioritisation of care for their teams, this proved not to be the case. A potential explanation is perhaps that larger teams meant less interpersonal contact with each team member and less opportunity to develop personal relationships. Alternatively, it may be that colleges purposefully allocated the largest span of control to those FTMs who displayed the characteristics of martyrdom - the more work a curriculum area would require, the more it needed someone who would work at the expense of their well being. As such, martyrs perceived resistance in direct relation to their aim of meeting all needs of the trialectic. Routine forms of resistance therefore had to be controlled to prevent a 
loss of control and damage to the student experience, the cohesion of the team and the accountability of their position. Unlike converts, however, martyrs did not view themselves as perpetuating acts of subjugation. The most vocal and overt of resisters themselves, they did not challenge resistance due to organisational identification or because senior managers wanted them to, they did it because certain forms of resistance were seen as damaging to the student experience. Of course, it may be that this was rationalisation on the part of martyrs - by identifying student welfare as the antecedent of challenging resistance they could avoid self-identification with senior managers; whether their teams understood their actions in the same way is, of course, debatable.

\section{References}

[1] Casey, C. (1995), Work, self and society: After industrialism. London: Sage.

[2] Jauhiainen, Arto and Alho-Malmelin, Marika (2004), "Education as a religion in the learning society", International Journal of Lifelong Education 23, no. 5, pp. 459-474.

[3] Fleming, P. (2005), "Metaphors of resistance", Management Communication Quarterly 19, no. 1, pp. 4566.

[4] Flanagan, J. C. (1954), "The critical incident technique”. Psychological Bulletin 51, no. 4, pp. 327-58.

[5] Page, D. (2011a), "Fundamentalists, priests, martyrs and converts: a typology of first tier management in Further Education", Research in Post-compulsory Education 16, no. 1, pp. 101-121.

[6] Emerson, M. and Hartman, D. (2006), "The rise of religious fundamentalism. Annual Review of Sociology 32 , no.1, pp. 127-44.

[7] Hirst, K. (2011) Priest, About.com: Archaeology, available

http://archaeology.about.com/od/pterms/qt/priest.htm (Access date: 14/07/12).

[8] Barry, J., Chandler, J. and Clark, H. (2001), "Between the ivory tower and the academic assembly line", Journal of Management Studies 38, no. 1, pp. 87-101.

[9] Wilson, F. (2002), "Dilemmas of appraisal", European Management Journal 20, no.6, pp. 620-629.

[10] Paloutzian, R., Richardson, J. and Rambo, L. (1999), "Religious conversion and personality change", Journal of Personality 67, no. 6, pp. 1047-1079.

[11] Camus, A. (2006), The Fall, London: Penguin Classics.

[12] Cook, D. (2007), Martyrdom in Islam. Cambridge: Cambridge University Press.
[13] Grant, A. (2007), "Relational job design and the motivation to make a prosocial difference", Academy of Management Review 32, no. 2, pp. 393-417.

[14] Willmott, H. (1997), "Rethinking management and managerial work: capitalism, control and Subjectivity", Human Relations 50, no. 11, pp. 1329-1359.

[15] Mumby, D. K. (2005), "Theorizing resistance in organization studies: a dialectical approach", Management Communication Quarterly 19, no. 1, pp. 19-44.

[16] Prasad, P. and Prasad, A. (2000), "Stretching the iron cage: The constitution and implications of routine workplace resistance", Organization Science 11, no. 4, pp. 387-403.

[17] Page, D. (2011b), "From Principled Dissent to Cognitive Escape: Managerial Resistance in the English Further Education Sector", Journal of Vocational Education and Training 63, no. 1, pp. 1-13.

[18] Collinson, D. (1997), "Strategies of resistance: power, knowledge and subjectivity in the Workplace" in J. M. Jermier, D. Knights, and W. R. Nord (Eds.), Resistance and power in organizations. Routledge, London.

[19] Avis, J. and Bathmaker, A.M. (2004), "The politics of care: emotional labour and trainee further education lecturers", Journal of Vocational Education and Training 56 , no. 1 , pp. 5-20

[20] Olson, E., Reger, S. and Singer, D. (2010), "Finding and reducing needless complexity", On the Horizon 18, no. 1, pp. 53-61.

[21] Goffman, E. (1971), Asylums, Middlesex: Pelican.

[22] Burawoy, M. (1979), Manufacturing consent: Changes in the labor process under monopoly capitalism. Chicago: University of Chicago Press.

[23] Page, D. (2010), "Power and resistance in Further Education: findings from a study of first tier Managers", Power and Education 2, no. 2, pp. 126-139.

[24] Contu, A. (2008), Decaf resistance: on misbehaviour, cynicism, and desire in Liberal Workplaces. Management Communication Quarterly 21, no. 3, pp. 364-379.

[25] Young, A. P. (2000), "ee I'm just mee: a study of managerial resistance". Journal of Organizational Change Management 13, no. 4, pp. 375-388.

[26] Fleming, P. and Spicer, A. (2003), "Working at a cynical distance: implications for power, subjectivity and resistance", Organization 10, no. 1, pp. 157-179.

[27] Graen, G. B. and Uhl-Bien, M. (1995), "Relationshipbased approach to leadership: development of leadermember exchange (LMX) theory of leadership over 25 years: applying a multi-level multi-domain perspective", Leadership Quarterly 6, no. 1,pp. 219-247. 